УДК 1(091):316.3

\title{
Н.Н. Равочкин
}

\section{ДИСКУРС ПОЛИТИКО-ПРАВОВЫХ ИДЕЙ В СЕТЕВОМ ОБЩЕСТВЕ: СОЦИАЛЬНО-ФИЛОСОФСКИЙ АНАЛИЗ (ЧАСТЬ 1)}

В статье обозначаются новые сущностные черты дискурса политико-правовых идей, приобретаемые им в реалиях сетевого общества. Отмечается, что функционирование данных интеллектуальных конструктов в пространстве конкретного общества или государства напрямую определяет эффективность институционального устройства, а также позволяет достигнуть власти различного прагматического эффекта. В качестве методологии исследования автор обращается к собственным синтетическим гносеометодологическим основаниям с основным упором на положениях социального реализма (Р. Коллинз, Н.С. Розов) и на акторно-сетевую теорию. Соответственно обозначенным подходам представлены механизм генезиса и логика бытия идей в социальном пространстве. Показаны специфика и характерные черты сетевого общества, что допускает также его прочтение как информационную модель социума. В Заключение работы обозначаются возможности дальнейшего исследования заявленной темы.

Ключевые слова: идея, политика, право, дискурс, современное общество, сетевое общество, техника, акторносетевая теория, социальный реализм, синтетическая методология.

DOI: $10.35634 / 2412-9550-2019-29-4-396-401$

\section{Введение}

Сообразуясь с повесткой времени рубежа XX-XXI вв., философия в очередной раз возрождает разработку «идейно ориентированной» проблематики исследований. Важность изучения множественного выражения идей, уже приведенных нами ранее к их прочтению как «философских оснований», несомненна, поскольку интеллектуальные конструкты включаются не просто в предмет метафилософии, но и социальной философии (для нас приоритетно направление практического воплощения идей в политико-правовую сферу), актуальность чего легко доказать хотя бы фактом значимости философских идей как детерминант социальных изменений [6]. Обращение к политико-правовой сфере вызвано авторской позицией, подчеркивающей приоритет легитимной власти, осуществляющей свою деятельность и соответствующие преобразования в других сферах соответственно обозначенному политическому курсу и актуальной вызовам времени законодательной базе. Отсюда следует, что социально-философские исследования генезиса и практического воплощения идей в обозначенной сфере имеют не только теоретическую, но и прикладную значимость.

Более того, исследователи не вправе игнорировать новые витки научно-технического прогрес$\mathrm{ca}$, существенно расширяющего и тем самым дополняющего проблемное поле современной социально-философской мысли. Многовекторность и многомерность динамики происходящих в индустриальном мире процессов относительно недавно подняли проблему формирования постиндустриальной модели социума, вариантами которого у разных мыслителей выступают следующие: «общество второго Модерна», «общество риска», «общество знаний», «(пост)информационное общество», «сетевое общество». Учитывая «сетевую» природу интеллектуальной деятельности, результатом которой становятся идеи, остановимся на последней в данном перечне модели.

Цель исследования - обозначить новые сущностные черты дискурса политико-правовых идей в контексте сетевого общества.

Достижение поставленной цели для первой части настоящего исследования задает императив обобщения характеристик сетевого общества.

\section{Обсуждение}

Политико-правовая сфера - одна из наиболее архаических областей человеческой деятельности, учреждение которой в Древнее время привело к появлению первых государств. Связь между политико-правовой сферой и идеями обнаруживает проблематику хотя бы в той части, что без четких представлений о желаемом государственном и социальном вариантах устройства и коммуникативных взаимодействий существование любого режима попросту не представляется возможным. Успешное и 
эффективное управление множественными потоками - идей и информации - сегодня стало основой цивилизованного достижения и удержания власти, если мы, конечно, говорим не про страны периферии, в ряде из которых, к слову, также отмечается смена курса на демократизацию. Идеи допустимо рассматривать как средство планирования и организации институциональных практик, регулирующих поведение индивидов и различных в социуме, при котором власть выступает контрагентом, требуя желаемого поведения в различных сферах деятельности.

Руководство таким подходом позволяет учесть и факты генезиса идей, и вербализацию их, и, что интересует нас более всего, - практическое воплощение интеллектуальных конструктов, приводящее к созданию властных институты: например, оформление института разделения властей. Итак, можно констатировать наличие достаточно видимой аналогии, поскольку продуцирование идей, как и идеологий, позволяет рассматривать их не беспристрастной фиксацией различных сторон действительности, а инструментом ориентации человека в развивающемся природном и социальном мире.

Мы долгое время рассуждали в ключе: «Почему же люди в ряде стран верят идеям одних субъектов власти, порой фактически “слепо" идя за ними, но аргументированные и разложенные по порядку позиции и убеждения, приводимые другими фигурами, в том же государстве попросту проходят мимо них как не представляющие интереса?». Ответ на подобный вопрос, по нашему мнению, - в особенностях осуществления рецепции идей, функционирующих в социальном пространстве абсолютно любого государства и общества. Например, наиболее быстро усваиваются и становятся убеждениями знания и ценности исключительно идентичные собственному опыту масс.

Мы учитываем, что процессы возникновения, дальнейшего развития и последующей трансформаций идей подразумевают также необходимость наличия в их содержании прагматики и сильных аксиологических оснований, способных к решению проблем и на уровне повседневности, и при более масштабных взаимодействиях. Соответственно нашей позиции, основанной на синтетической социально-философской методологии, а также на принципах исторической макросоциологии, будем полагать, что идеи не значимы «сами-для-себя» и важны не только для отдельных людей, которые заняты их продуцированием и могут называться «идеологами», «интеллектуалами», «политтехнологами», «пропагандистами», но и для всего социума.

Отмеченное нами лишь добавляет актуальности ввиду перманентно усложняющихся параметров общепланетарного бытия современности, приводя к увеличению степени неизвестности и рисковости, а также невозможности осуществить сколько-нибудь ясное прогнозирование развития на уровне государств, регионов и мира хотя бы в кратко- и среднесрочной перспективах. Мы уверены, что современный мир увеличивает разрывы между реальной жизнью и властными инициативами, тем самым детерминируя определенный аксиокризис для политико-правовой сферы, иногда выливающийся в так называемый «побег за бессмысленными инициативами и решениями». Обращение к характерным чертам дискурса политико-правовых идей в рамках социально-философского анализа позволит, на наш взгляд, не только получить какие-то предельные основания для траекторий развития государств «ядра», но и, в условиях глобализации, наметить пути решения проблем мирового масштаба.

Ранее проведенный анализ различных методологических установок дает возможность исходить из ряда положений на предмет необходимости учета множества вариаций реализующихся в социуме процессов. Так, одним из них элементов создаваемых нами новых гносеометодологических оснований выступают положения теории Р. Коллинза о генезисе идей, возникающих, существующих и трансформирующихся в социуме. Мы уже отмечали, что рассматриваемые интеллектуальные конструкты - это результат той или иной социальной детерминированности в виде четко определенных схем.

Применительно к данному замечанию уместно привести позицию профессора Н.С. Розова, уточняющего, что идеи возникают как «особые социальные реальности, возникающие при определенных условиях в некоторых сообществах» [7. С. 7]. Вполне логичным выглядит, что при постижении генезиса идей как таковых необходимо сосредоточиться на совокупности факторов (географических, социокультуных, политических, экономических и др.), поскольку ведущие детерминанты возникновения каждой идеи могут быть определены только в зависимости от конкретной ситуации. В этом ключе инструментальное значение для изучения идей вообще и их практической реализации представляет построенная Розовым четырехчастная социальная онтология, выделяющая материальный мир, психосферу, культуросферу и социосферу. Проводя соединение идей с «социальной воображаемостью» и четкой завязкой на географической локализации интеллектуальных сетей и центров, новосибирский философ утверждает, что генезис идей, значимых для социального развития, «в одних 
местах планеты Земля может произойти, а в других - нет, и даже если бы случился, никто бы об этом не узнал» [7. С. 31]. В последующем эти результаты сетевой мыследеятельности используются интеллектуалами как основа для производства идей, опять же - с привязкой к определенной сфере социума и конкретного государства, а также при формировании нового мировоззренческого аппарата.

С учетом приведенной позиции Розова гораздо проще понять и другую сторону коллинзовской теории, связанную с положением, что абсолютно любая историческая эпоха уникальна и тем самым детерминирует своими актуальными проблемами и злободневными вызовами содержание идей конкретного интеллектуала. В отличие от большинства исследователей, отмечавших ограниченность существования идей (и их соответствующего последующего выбытия из дискурса), возникающих и развивающихся только благодаря вкладу двух-трех поколений, для Коллинза очевидна их возможная актуализация и долгосрочное удержание в социальной практике, что заставляет обратить внимание на плюрализм самых разнообразных детерминаций при продуцировании идейных конструктов.

Кроме того, коллинзовское понимание генезиса и оформления идей во многом определяется синкретизмом внутреннего и внешнего факторов. Так, с одной стороны, обеспечивается включенность конкретного интеллектуала и его потенциала в систему интерсубъективных связей, что позволяет констатировать включенность его мыслительных возможностей в единую систему, связанную с продуцированием идей.

Обратимся далее к социальным институтам как общественным структурам для обеспечению порядка, ожидающих и крайне заинтересованных в итогах мыследеятельности интеллектуалов, поскольку к ним предъявляются повышенные требования в части теоретического обеспечения успеха и эффективности функционирования конкретного государства. Приведенный факт позволяет интеллектуалам через профессиональную среду влиться в систему связанных с властью отношений, сохранив себя полностью и получив поддержку от заинтересованных организаций. Таким образом, на стыке четырех элементов у нас появляется возможность констатировать инструментальную природу идей, связанных с социальными преобразованиями в различных сферах жизни общества. Говоря развернуто, интеллектуальный конструкт обретает потенциал не только своего появления, но и развития, и последующего применения (как правило, в сочетании с другими идеями) на практике, а также переживания трансформаций, создающих их новые варианты - идейные модификации и конфигурации.

Еще один включаемый в обозначенную методологию тезис связан с акторно-сетевой теорией и заключается в том, что интеллектуальная история в рамках этой концепции может определяться как процесс, детерминированный двумя точками зрения, успешно дополняющими друг друга. Во-первых, интеллектуалы, создавая принципиально новые идеи, весьма заметно воздействуют на социальное развитие. Такое утверждение справедливо, поскольку уже отмеченная нами в предыдущих работах идейная детерминация общественных процессов и преобразований закономерно отражает развитие социума и, как следствие, иллюстрирует этим воплощение интеллектуальной истории. Во-вторых, само понимание сущности материальных объектов, используемых в обществе, не как предметов, испытывающих на себе постоянное воздействие со стороны субъектов, но именно как акторов, которые на началах равенства и даже «равноправия» участвуют в изменениях социальной ткани и всей интеллектуальной истории [5]. Тем самым, материальные объекты, оказывая воздействие на интеллектуалов, вынуждают последних трансформировать продуцируемые ими идеи, а также осуществлять уже отмеченные идейные модификации.

Согласно таким положениям, сформулируем в настоящей работе цель исследования как концептуальное осмысление дискурса идей и политико-правовых практик в прочтении современного общества как «сетевого». Термин «сетевое общество» может быть определен также через «информационное» (Д. Белл [2] и М. Кастельс [3;4]), поскольку здесь реализуются почти те же основные принципы идейного дискурса. Например, исследования приводят к формированию новых, всё более совершенных технических средств, проникающих в социальную ткань, обеспечивая его развитие. Это касается и акторов, равноправно участвующих в формировании действительности, вне зависимости, рассматриваются здесь социальные субъекты или уже созданные технические объекты. Таким образом, построение соответствующей данному исследованию методологической базы осуществляется на основе синтетической методологии и исторической макросоциологии, дополняемой общефилософскими методами: синтеза, а также диалектическим, сравнительным и прагматическим.

Обсуждение полученных результатов начинаем с установления исследователем А.С. Соколовой содержательного тождества информационной и сетевой социальных систем, где приоритетны не 
те элементы, которые определяют ее существование. Говоря обобщенно, она указывает, что сеть это система как целое, а образуемые между узлами связи представляют собой ее элементы. Причем в сетях минимальное количество звеньев равняется трем, а наименьшее число связей - двум. Отношения, таким образом, становятся результатом единой связи двух звеньев [8].

При сетевом подходе индивиды образуют узлы, а социум представлен в виде сложно организованной системы. В то же время ввиду узлов (автономных образований) происходит и характерная для современного нам социума децентрализация. Отсюда очевидно, что общество в его прочтении через «структуру», в самом деле, перестает зависеть от определенных субъектов, в соответствии с чем, привычные для индустриальной модели элементы уже не создают сильных детерминационных связей, определяющих сущность этой системы. Теперь системой является именно сеть, которая одновременно с этим - определяющий элемент для всех субъектов, к которым относят людей, социальные группы, различные классы, а порой и целые страты. Логика развертывания положений сетевого подхода способствует генезису социальной детерминанты, выходящей на более высокий уровень, чем отдельный набор интересов [4]. Объясняется это тем, что подобные «наборы» всё еще создают определенные функциональные ограничения субстанциональной позиции, согласно чему достигается реализация лишь незначительной части интересов акторов. Претензия и пафос сетевого общества заключаются в его устремлениях попытаться раскрыть полный функционал, который бы привел к примату социальной морфологии над отдельными действиями [3]. Как результат отсюда - постепенная замена деятельностного подхода системным. На наш взгляд, это подтверждение общеизвестного тезиса о том, что индивидуальная деятельность менее эффективна, чем та, в которой будет участвовать вся сеть.

Итак, для сетевой модели становится характерным, что даже сложившаяся и укоренившаяся для конкретного общества система взаимоотношений не позволяет определить сущность всех социальных артефактов, создаваемых и участвующих в плюрализме протекающих в нем процессов. Кстати, в данной модели социума всё это касается и человека, включаеющегося в нее и тоже становящеегося артефактом, как новая модель компьютера. Сущность включаемого в систему артефакта формируется под воздействием окружающей его информационной среды и множества акторов как «узлов системы» [10]. Последние элементы обретают значимость, поскольку поддерживают стабильность системы: «Вещи <...> не могут игнорироваться при изучении социальных процессов, поскольку их характеристики во многом определяют саму возможность интерсубъективного взаимодействия и условия её осуществления〉 [1. С. 128]. Итак, прочтение акторно-сетевой теории выглядит как нечто среднее между концепциями элементов и отношений [9]. Сильная сторона акторно-сетевой теории выражается посредством возможностей осуществления сборки положений этих концепций, тем самым, выявляя значение не только отдельного субъекта социального процесса, но и всей системы отношений, в которой бытийствует актор.

Определяя сущность сетевого общества, необходимо обратиться к его следующим характерным свойствам:

- Компьютерная грамотность и доступ к ИКТ как определяющие критерии жизнеспособности (отнесенность к определенной социальной страте заменяется на профессию, производные от которой - экономический успех и круг общения (социально-психологический маркер)) индивидов, групп и целых обществ;

- Переориентация фундамента социальной системы на горизонтальные схемы взаимодействий взамен привычных для большинства вертикальных отношений;

- В основу социального неравенства заложена дифференциация по уровню доступа к современным технологиям, фактически исключающая группы индивидов из системы общественных отношений [8];

- Появление виртуальной реальности как нового поля взаимодействий, выступающей оппозицией объективному миру

- Кризисная и динамичная природа трансформирующихся аксиологических оснований социального бытия, связанных с перманентными технико-технологическими изменениями (экономический успех, общество потребления модных гаджетов, гонка вооружений, жизнь в стиле «реалити шоу» - всё это детерминировано технологическими новациями) [11].

Мы видим, что причиной-определителем не только собственного генезиса, но и развития вообще, сетевая модель современного общества имеет техническое переоснащение социальной ткани. У нас не возникает сомнений, что отмеченные нами глубинные и радикальные перемены создают мно- 
жество затруднений в плане привычной, являющейся для большинства населения планеты «нормальной», организации социального бытия. Не будут исключением и сложности, возникающие непосредственно в жизни каждого человека, сопряженные с преобразованиями в части соотношения «публичное - частное». Разумеется, социальная динамика маркирует обозначенный переход в сетевой модели не иначе, как «быстрый». Саратовский философ Д.А. Аникин отмечает утрату индивидом личного (приватного) пространства, однако, порой сам того не желая и даже не всегда осознавая, он получает «взамен излишнюю публичность и становясь точкой пересечения самых неожиданных идентичностей» [1. С. 129]. Результатом для каждого индивида, который не может принять новый порядок вещей в объективной реальности, будут социально-психологические трудности, ранжирование и преодоление которых ложится только на них.

\section{Возможности дальнейшего исследования}

Выявленные в настоящей работе характерные черты сетевого общества позволяют читателям увидеть теоретическое основание для выявления новых сущностных черт дискурса политико-правовых идей. Согласно авторскому видению сетевого варианта модели социума, вторая часть исследования будет ориентирована на достижение общей цели исследования, в которой пристальное внимание будет обращено на трансформацию дискурса власти в ее сопряжении с технико-технологическим развитием.

\section{СПИСОК ЛИТЕРАТУРЫ}

1. Аникин Д.А. Сетевые основания социальной памяти // Известия Саратовского университета. Новая серия. Серия: Философия. Психология. Педагогика. 2017. Т. 17. № 2. С. 129-134.

2. Белл Д. Грядущее постиндустриальное общество. Опыт социального прогнозирования. М.: Academia, 2004. $788 \mathrm{c}$.

3. Кастельс М. Информационная эпоха: экономика, общество, культура [Электронный ресурс]. Режим доступа: URL: http://www.gumer.info/bibliotek_Buks/Polit/kastel/intro.php (Дата обращения: 05.10.2019).

4. Кастельс М. Могущество самобытности. Становление общества сетевых структур // Новая постиндустриальная волна на Западе: антология / ред. В.Л. Иноземцев. М.: Academia, 1999. С. 494-505.

5. Равочкин Н.Н. Осмысление истории развития идей с позиции акторно-сетевой теории // Вестник Бурятского государственного университета. 2019. № 1. С. 59-66.

6. Равочкин Н.Н. Философские идеи как детерминанты социальных изменений // Социально-политические науки. 2018. № 6. С. 97-100.

7. Розов Н.С. Идеи и интеллектуалы в потоке истории: макросоциология философии, науки и образования. Новосибирск: Манускрипт, 2016. 344 с.

8. Соколова А.С. Концепция сетевого общества в рамках цивилизационного подхода // Вестник Ленинградского государственного университета им. А.С. Пушкина. 2015. Т. 2. № 4. С. 234-242.

9. Czarniawska B. Bruno Latour and Niklas Luhmann as organization theorists // European Management Journal. 2017. № 35. pp. 145-150. https://doi.org/10.1016/j.emj.2017.02.005

10. Evans A. Politicising inequality: The power of ideas // World Development. 2018. № 110. pp. 360-372. https://doi.org/ 10.1016/j.worlddev.2018.06.006

11. Mendonça S., Crespo N. Simões N. Inequality in the network society: An integrated approach to ICT access, basic skills, and complex capabilities // Telecommunications Policy. 2015. № 39. pp. 192-207. https://doi.org/10.1016/ j.telpol.2014.12.010

Равочкин Никита Николаевич, кандидат философских наук, доцент кафедры гуманитарно-правовых дисциплин ФГБОУ ВО «Кузбасская государственная сельскохозяйственная академия» 650056, Россия, г. Кемерово, ул. Марковцева, 5

E-mail: nickravochkin@mail.ru 


\section{N.N. Ravochkin \\ DISCOURSE OF POLITICAL AND LEGAL IDEAS IN A NETWORK SOCIETY: SOCIO-PHILOSOPHICAL ANALYSIS (PART 1)}

DOI: $10.35634 / 2412-9550-2019-29-4-396-401$

The article identifies new essential features of the discourse of political and legal ideas, acquired by it in the realities of a network society. It is noted that the functioning of these intellectual constructs in the space of a particular society or state directly determines the effectiveness of the institutional structure, and also allows the authorities to achieve a different pragmatic effect. As a research methodology, the author turns to his own synthetic epistemic-methodological foundations, focusing on the provisions of social realism (R. Collins, N.S. Rozov) and actor-network theory. In accordance with the indicated approaches, the mechanism of genesis and the logic of the existence of ideas in the social space are presented. The specificity and characteristic features of a network society are shown, which also allows its reading as an information model of society. In conclusion, the work outlines the possibilities for further research on the claimed topic.

Keywords: idea, politics, law, discourse, modern society, network society, technology, actor-network theory, social realism, synthetic methodology.

Ravochkin N.N., Candidate of Philosophy, Associate Professor at Department of Humanities and Legal Disciplines

Kuzbass State Agricultural Academy

Markovtseva st., 5, Kemerovo, Russia, 650056

E-mail: nickravochkin@mail.ru 